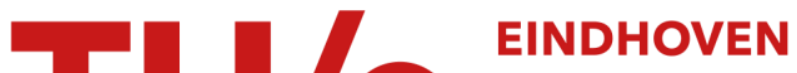 UNIVERSITY OF TECHNOLOGY
}

\section{The instrument as the source of new in new music}

Citation for published version (APA):

Andersen, K., \& Gibson, D. (2017). The instrument as the source of new in new music. Design Issues, 33(3), 3755. https://doi.org/10.1162/DESI_a_00450

DOI:

10.1162/DESI_a_00450

Document status and date:

Published: 01/07/2017

\section{Document Version:}

Publisher's PDF, also known as Version of Record (includes final page, issue and volume numbers)

\section{Please check the document version of this publication:}

- A submitted manuscript is the version of the article upon submission and before peer-review. There can be important differences between the submitted version and the official published version of record. People interested in the research are advised to contact the author for the final version of the publication, or visit the $\mathrm{DOI}$ to the publisher's website.

- The final author version and the galley proof are versions of the publication after peer review.

- The final published version features the final layout of the paper including the volume, issue and page numbers.

Link to publication

\section{General rights}

Copyright and moral rights for the publications made accessible in the public portal are retained by the authors and/or other copyright owners and it is a condition of accessing publications that users recognise and abide by the legal requirements associated with these rights.

- Users may download and print one copy of any publication from the public portal for the purpose of private study or research.

- You may not further distribute the material or use it for any profit-making activity or commercial gain

- You may freely distribute the URL identifying the publication in the public portal.

If the publication is distributed under the terms of Article 25fa of the Dutch Copyright Act, indicated by the "Taverne" license above, please follow below link for the End User Agreement:

www.tue.nl/taverne

Take down policy

If you believe that this document breaches copyright please contact us at:

openaccess@tue.nl

providing details and we will investigate your claim. 


\section{The Instrument as the Source of New in New Music Kristina Andersen, Dan Gibson}

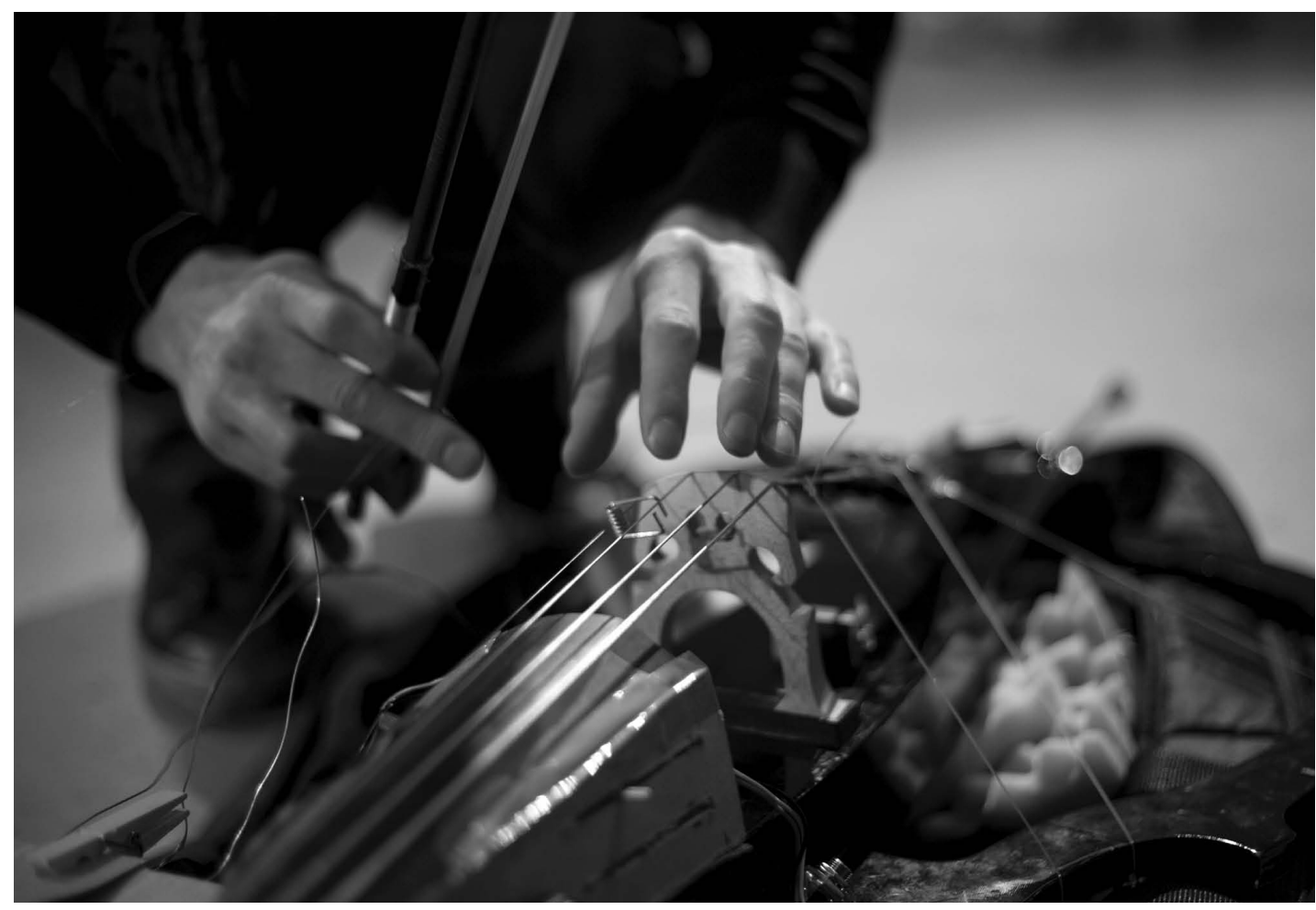

Figure 1

An investigation into the modification of the cello. Image (C) Dan Buzzo.
"The musical instrument is a vehicle for the desire to make music. It is both something that must be internalized, incorporated, and made flesh and something other, without which we could not get to that sound from the world beyond."1

Joel Ryan

\section{Introduction}

This text describes an embodied design process conducted as a collaboration between a musician, Dan Gibson, and a researcher, Kristina Andersen. The process takes its origin in the musician's desire to rebuild and re-imagine a cello as the site for both the generation of musical sound, and the complex modification and processing of that sound through software (see Figure 1). The underlying concern is not just to improve an existing instrument or to make it suitable for electronic music, but to create structures that might fit better with the artist's personal mental images of the music that could be produced. As such, we are not directly 
2 Kristina Andersen and Dan Gibson, "The Instrument as the Source of New in New Music," in Proceedings of the 2nd Biennial Research Through Design Conference, Cambridge, UK, March 25-7, 2015, DOI: 10.6084/m9.figshare.1327992.

3 For these three sources of inspiration, see Augusto Boal, Games for Actors and Non-Actors (London: Routledge, 1992); Victor Shklovsky, "Art as Technique" (1917), Russian Formalist Criticism: Four Essays, trans. Lee T. Lemon and Marion J. Reis (Lincoln, NE: University of Nebraska Press, 1965); and John Dewey, Art as Experience (New York: Putnam, 1958), respectively.

4 For placebo designs, see Anthony Dunne and Fiona Raby, "The Placebo Project," in Proceedings of the 2002 Conference on Designing Interactive Systems (New York: ACM, 2002), 9-12. DOI: 10.1145/ 778712.778714. For future technology workshops, see Giasemi N. Vavoula, Mike Sharples, and Paul D. Rudman, "Developing the 'Future Technology Workshop' Method," in Proceedings of the International Workshop on Interaction Design and Children, Eindhoven, Netherlands, August 28-29, 2002. For cultural probes, see Bill Gaver, Tony Dunne, and Elena Pacenti, "Design: Cultural Probes," Interactions 6, no. 1 (1999): 21-29. DOl: 10.1145/291224. 291235.

5 For details on these earlier experiments, see Kristina Andersen and Danielle Wilde, "Circles and Props: Making Unknown Technology," Interactions 19, no. 3 (2012): 60-65. DOl: http://dx.doi. org/10.1145/2168931.2168944; Kristina Andersen, "Making Magic Machines," in Proceedings of the 10th European Academy of Design Conference, Göteborg, Sweden, April 17-19, 2013; and Kristina Andersen, "The Deliberate Cargo Cult," in Proceedings of the 2014 Conference on Designing Interactive Systems (New York: ACM, 2014), 627-36. DOI: 10.1145/2598510.2598596. concerned with traditional usability issues, such as potential increases in efficiency; instead, we aim for increased flow, intuitive modes of expression, and unbroken periods of concentration in the experience of playing music. This description of our collaborative work process is an extension of a paper initially presented at the Research Through Design (RTD) 2015 conference. $^{2}$

\section{Methodology and Context}

The project was conducted in an art setting at STEIM, a studio for electro-acoustic music in Amsterdam. The focus of the work done at the studio is to use any available technologies and techniques to facilitate artists' building of new instruments for their own musical practice. Our community tends to focus on improvised and experimental electronic music centered on live performance. In this setting, it is natural for us to make use of a broad range of techniques from theater, dance, and performance. We take inspiration from the experimental theater work of Boal, the art practice of estrangement as described by Shklovsky, and Dewey's notion of experience as a process of becoming. ${ }^{3}$

This type of work is similar to critical design methods (such as placebo designs), practical methodologies (such as future technology workshops), and techniques for inspiration and understanding of users (such as cultural probes). ${ }^{4}$ Our techniques of ideation also draw on traditions of craft and making, aimed at facilitating situations in which the development of new ideas is not primarily verbal in nature but takes place through the making of maquettes and sketches. In addition, the notion of technology as a "magical unknown" is the starting point for a range of our earlier experiments with techniques of material exploration. ${ }^{5}$ In this particular case, we specifically use the making of nonfunctional mock-ups as a way to imagine a technological/musical element that is yet to be built. These mock-ups then act as props through which participants can express their intuitions and concerns with a given technological or musical notion. This text is illustrated by a series of images showing the various stages and aspects of the project.

\section{Making New Instruments}

From our position, a new instrument provides an intuitive interface between gesture and sound; it allows for the development of virtuosity, which we see as the capacity of achieving new levels of nuance and sensitivity through time and practice. In this way, a new instrument can provide long-lasting and fulfilling interactions that exceed the novelty of its modifications and extensions. Similarly, a new instrument should be capable of surprising the performer and allowing the continual renewal of musical possibilities through exploration, practice, and discovery. Such an 
instrument also requires a certain level of stability and durability, providing the longevity suitable for traveling and performing. It should also provide a sense of reliability to allow the performer to act with immediacy, focusing on aesthetic and musical considerations rather than the technical details that lie behind the interface.

In the playing of an instrument, whether a traditional or a new one, the body of the performer is in the center of things, with the control and sound properties of an instrument intimately linked to its acoustical properties, technical execution, size, weight, and construction. (See also Gibson's theory of affordances. ${ }^{6}$ ) Considering new technology for creative expression through the framework of objects and instruments allows us to address the potential design and solution space through the performing body of the musician.

To facilitate such an initial embodied conversation about new instruments for creative expression, we build tentative and hypothetical instruments as non-functional physical mock-ups and prototypes. Each resulting hypothetical instrument reveals new strengths and weaknesses in a proposed instrument design; and more importantly, the process temporarily frees us from considering practical and technical limitations and concerns.

\section{Non-Functional Prototypes}

In our work, we use physical making as a way of thinking with our hands and then letting the resulting object support the imagining and talking about any underlying ideas that might not be fully understood yet. The resulting objects can be seen as active props, animated and investigated by playing them. The props allow us to fantasize and guess about their functionality and use. Certain features will be accidental, dictated by the limited material available and the short construction time, but as the maker stands up to explain and "play," all features (intended and unintended) work together to inspire and inform the presentation. In that moment of heightened awareness, the prop itself instructs the maker as to how it should be handled and used.

This process uses mechanics similar to pretend play: the

6 James J. Gibson, "The Theory of Affordances," in Perceiving, Acting, and Knowing: Toward an Ecological Psychology, eds. Robert Shaw and John Bransford (Hillsdale, NJ: Lawrence Erlbaum, 1977), 67-82.

7 Angeline S. Lillard, "Pretend Play Skills and the Child's Theory of Mind," Child Development 64, 2 (1993): 348-71.

8 Augusto Boal, Games for Actors and Non-Actors (London: Routledge, 1992).

9 Roger Caillois, Man, Play, Games, trans. Meyer Barash (Champaign, IL: University of Illinois Press, 1961). ability to represent one object as two things at once, the ability to see one object as representing another, and the ability to represent mental representations. ${ }^{7}$ The child knows that the stick in his hand is just a stick, and yet at the same time, within the game, it is also a sword. We can hold these two realities at once; they are both in some sense true simultaneously. This perspective mirrors Augusto Boal's games in which listening and paying attention allow the players to gather knowledge through improvisation. ${ }^{8}$ It is, in turn, reminiscent of Callois's game spaces, in which we can erect a tent in time where experimentation can take place. ${ }^{9}$ 


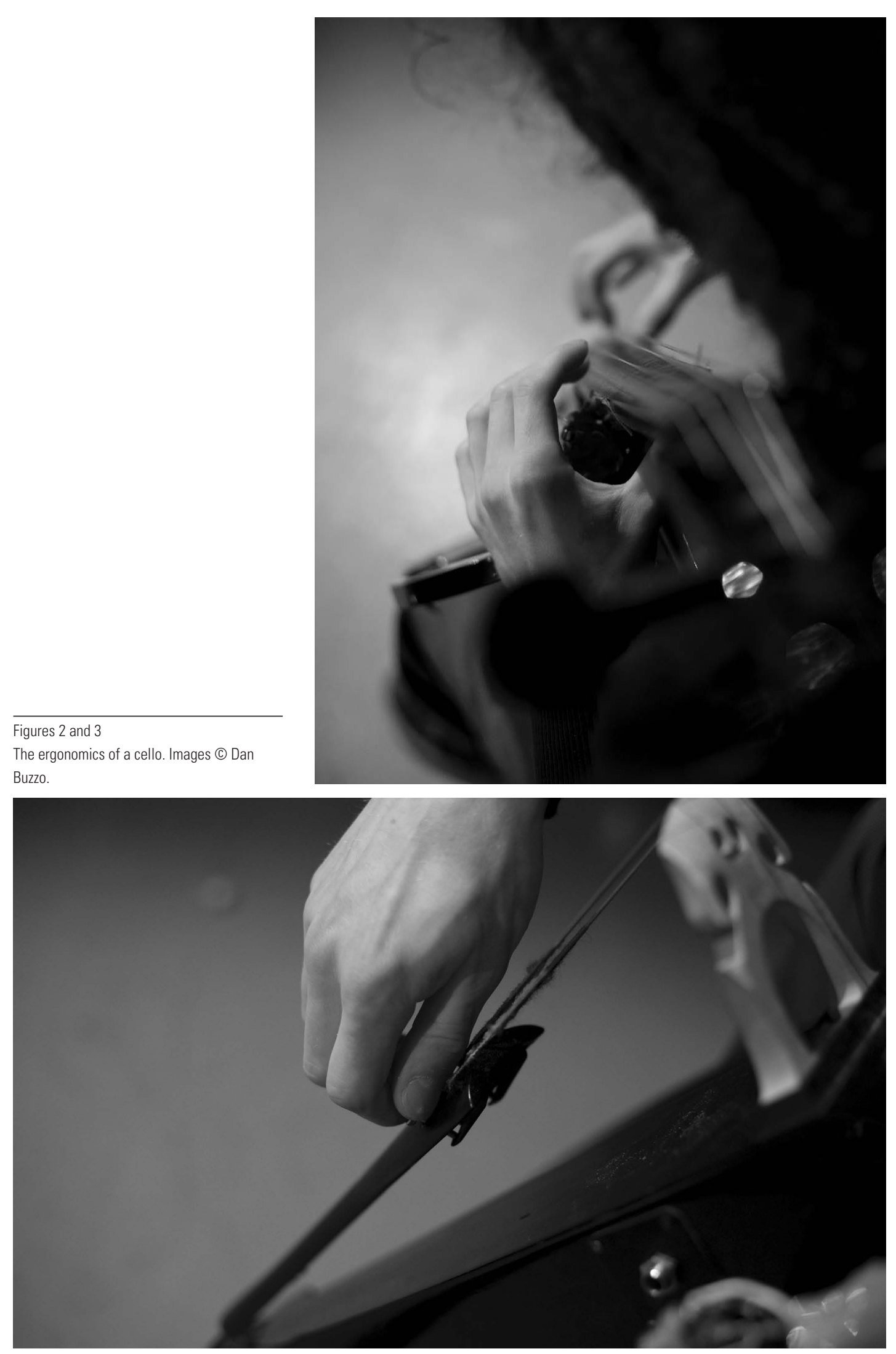

Design/ssues: Volume 33, Number 3 Summer 2017 


\section{The Cello}

The cello was chosen by the musician as point of departure due to both its physical form and its tonal qualities (see Figures 2 and 3). For the purpose of this project, it acts as both a sound source and a physical interface for the real-time creation of improvised electronic music. A long list of qualities makes the cello uniquely suited for such an exploration:

- Musically, the cello offers a wide range of sounds and intuitive control over subtle transformations of the sound's timbre and texture. More specifically, the range of percussive and tonal sounds that can be made using the bow and fingers offers many possibilities for producing sound-for example, plucking, bowing, scratching, bouncing, tapping, and scraping.

- The different materials, shapes, and edges of the bow allow for different playing techniques, producing a wide range of percussive and tonal, continuous and discontinuous sounds. The use of the bow also amplifies the performer's movements, allowing for subtle manipulations of the sound.

- Ergonomically, the large size of the fret board provides a high resolution for the control of pitch, allowing very small movements to make significant tonal differences. In addition, the amount of finger and bow pressure applied to the strings results in diversity in the density and spectral content of the sound.

- Finally, the quieter tapping and scratching sounds produced by playing the bridge directly have a more direct and close quality sonically, picking up more detail and complementing the thicker, fuller sound of the strings. The complexity and interdependence of these aspects lead to a deeply engaging and responsive interaction with the instrument, while retaining intuitive control of the sound.

\section{Collaboration Process Notes:}

My experiences with improvising and playing acoustic instruments led me to an interest in real-time electronic music. The detailed and expressive control of the cello is well suited to this exploration and provides a wide range of possibilities for transformation using software.

Processing the sound electronically provides the potential for creating more dynamic transitions and transformations to the cello sound.

I used to achieve this effect by using a separate commercial interface with sliders and switches to modify the sound from the cello. Because the cello usually requires two hands to fully articulate the acoustic sound, reaching over to 


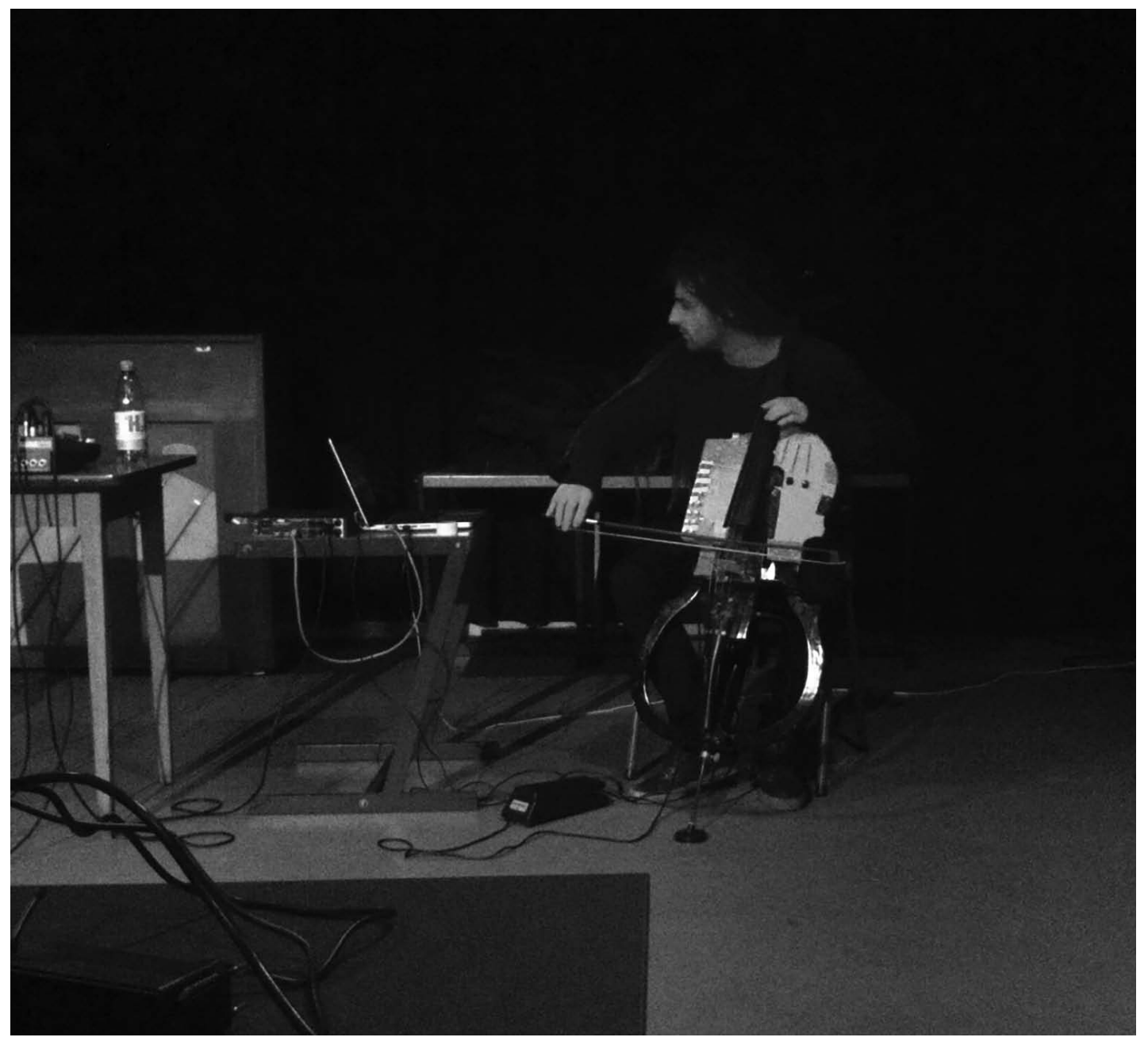

Figures 4 and 5

Understanding the cello and drawing the sound. Images (c) Dan Buzzo.

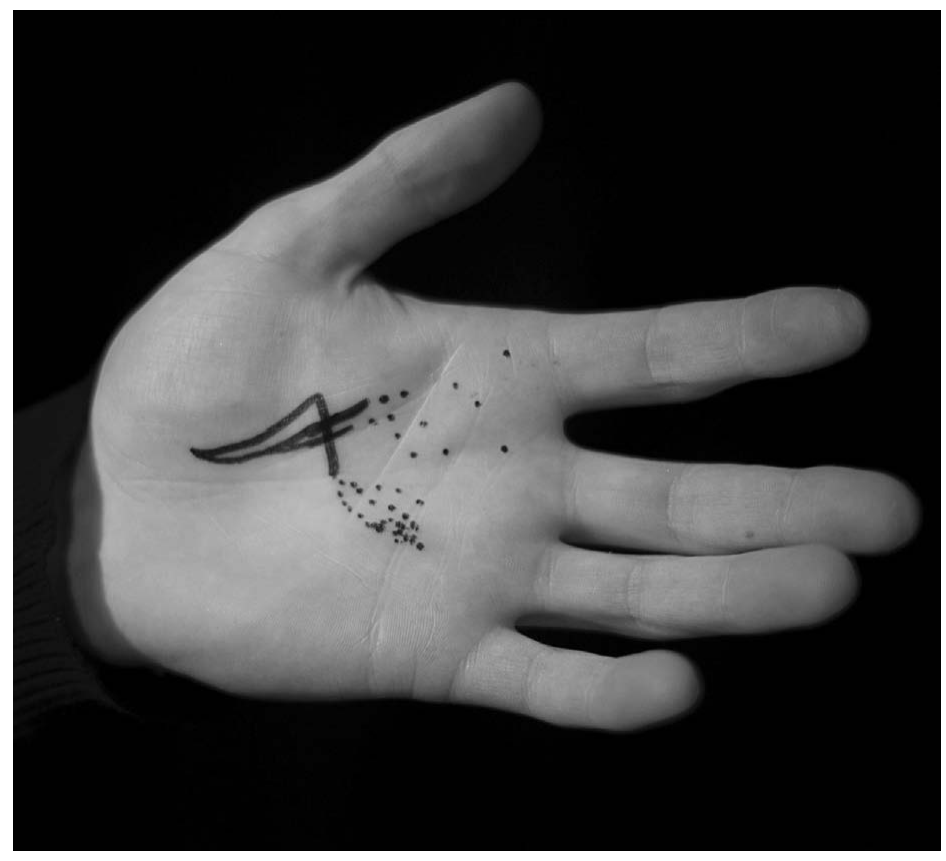


the controller creates a break in the flow of the performanceboth cognitively and physically. This break is problematic during improvisation because acting spontaneously and intuitively becomes difficult (see Figure 4).

My first explorations of the cello involved developing an understanding of the instrument's sonic and physical properties through playing, practice, and reflection.

\section{Understanding the Unmodified Instrument}

We began this work process by reconsidering the qualities of the existing, unmodified cello. By examining and exploring traditional playing techniques and their associated sonic qualities, we developed a shared understanding of what is and is not possible in the instrument's initial state. In particular, the relationship between the bodies of the cello and performer were considered so that issues of balance and stability revealed themselves as significant. While playing in the traditional posture, the performer is required to support the instrument to prevent it from falling. This means that the instrument must be stable enough to support the pressures exerted by the performer and to allow freedom of movement around the cello body.

The movements made by the performer and the resultant sounds were analyzed to gain a better understanding of the limits of stability and the connections between sound and gesture. The cello is a relatively large instrument, and although this size is advantageous and provides a high-resolution control of pitch, the physical distance between the note-positions on the cello body requires significant time for each transition movement. The instrument also requires both hands if it is to be played in the traditional manner, with the player's control and articulation severely compromised when using only one hand.

\section{Collaboration Process Notes:}

The cello revealed itself through different perspectives/modes of interaction, and this revelation helped me to build an embodied and conceptual knowledge of the instrument's affordances and limitations. This process focused on stability, balance, and symmetry between the body of the instrument and my own.

These initial explorations helped to identify which aspects of the instrument could be modified and extended while also revealing which elements are crucial to the functioning and identity of the cello.

Draw the sound you want to be able to make. Drawing directly on the hand is a gesture similar to a musical gesture in improvised music (see Figure 5). The action leaves no room for hesitation, and the result is both surprising and well 


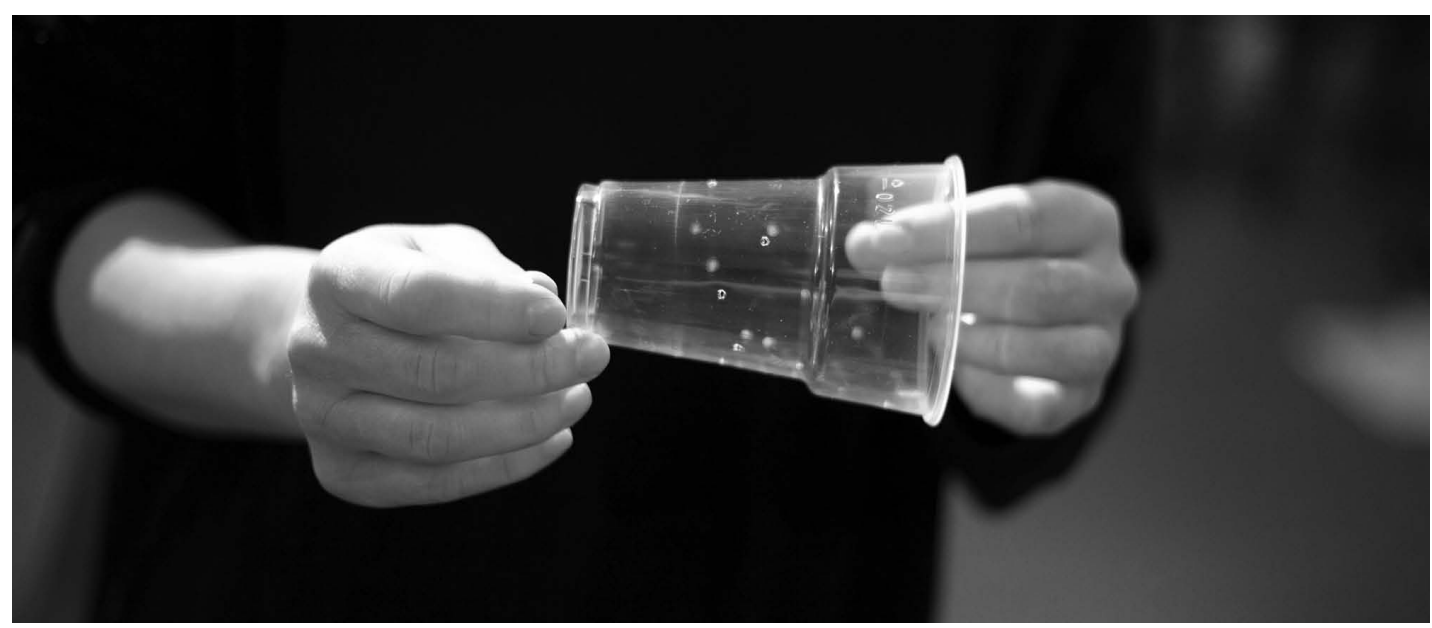

Figure 6

Conceptual model of sound processing. Image (c) Dan Buzzo. known. Abstract conceptions of time now can be examined in the physical domain, expanding perspectives and developing strategies.

\section{Processed Sound}

In electro-acoustic music, electronics can be seen as a way to free the performer from the need to transfer energy into the instrument continuously to produce sound. The use of delays and sampling allows for the creation of layers and iterative transformations, building momentum and references in time, which in turn manipulate the sense of direction in the music. These practices allow the performer to produce and manipulate sound in multiple time domains and playing modes. Amplification allows us to magnify the input energy provided by the performer and to draw attention to the quieter sounds and textural details. Similarly, compression and distortion add weight, impact, and density to the sound. In comparison, the use of filtering allows for reductions to be made in the spectrum of the sound, accentuating the tonal and textural differences that can already be made with the bow (see Figure 6).

Throughout this work process, we approached the evolving new instrument as a platform for exploring the combination, connections, and interaction between acoustic and electronic sounds. By focusing on the transition between gestures and playing modes, as well as on the various ways the existing cello can be played as an object, removed from its historical context, we were able to imagine and develop each modification and extension. Meanwhile, the exploration of different sound-making techniques and the possibilities of combining them in a sonically interesting way provided us with an emerging vocabulary of new musical gestures.

\section{Collaboration Process Notes:}

As a dialogue developed between me and the instrument, I could imagine extensions and transformations to the sound 
Figure 7 and 8

Conceptual cello models. Images (C) Dan Buzzo.
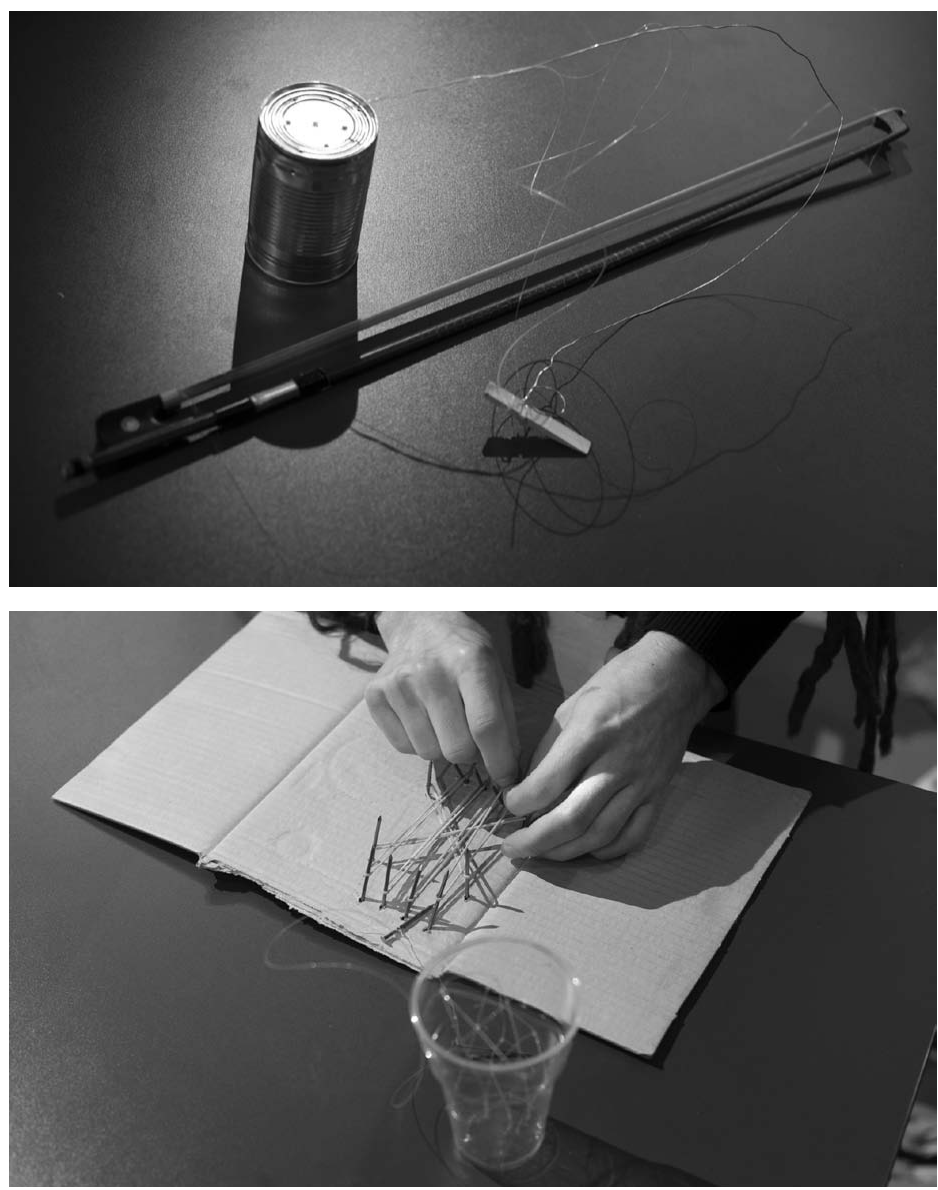

and gestures. In this way, the act of playing remains the main source of momentum and evaluation for the project and ensures an integration between the new and the old vocabularies of technique.

We focused on the subtle and detailed means of control over a wide range of sounds that the bow makes possible, including adding extra strings to the cello and cutting notches into the bow itself. By experimenting with different materials for the strings, I became aware of their different abilities and the subtleties of friction and pressure that are involved in controlling the sound.

The instrument integrates acoustic and digital elements using a combination of audio analysis and interrelated mappings. This integration allows the software to create either complementary or contrasting reactions in the resultant sound through the introduction of noise and probabilistic functions.

\section{Making the Instrument Malleable}

To identify the functionality and properties of the cello's fundamental components, we built a series of explorative conceptual models. These simple string instruments mimic aspects of size, 
movement, and material qualities of the cello. Through this technique, the instrument becomes malleable, and we gain a clearer understanding of the origins of its physical form. These simplified instruments allow us to twist, bend, and manipulate the different elements, exploring the affordances and limitations of the shapes and materials.

We used this dissection method as a way to conduct an internal analysis aimed at finding the limits of the original instrument: How much can we remove and modify the cello before it is no longer a cello? This type of reduction helped to temporarily remove the strong identity of cello and reveal new possible directions for its future development. Conversely, this process also informed us about what aspects of the design are essential to the functioning and identity of the cello in its original state.

Our experimentations revealed that the modes of interaction that are used significantly contribute to the identity of the instrument itself. In particular, the construction and exploration of the simple models showed that the gestures and orientation between the musician and the instrument are a fundamental factor. In the creation of increasingly abstract and reduced models, this relationship between performer and instrument became clearer, allowing us to identify and explore the boundaries while starting to reshape them (see Figure 6).

\section{Collaboration Process Notes:}

By building a series of conceptual models of the cello, we reduced it to its fundamental components, so that we could gain a better understanding of the functionality and physical processes involved in the instrument (see Figures 7 and 8).

We experimented with resonance, vibration, and physical stance by constructing and playing cello-like devices made from cups, cans, string, and elastics. We did so to explore the instrument from different angles and to reveal the extent to which each orientation between the cello and the performer constricts or frees the experience of playing.

The elasticity, malleability, and structure of interwoven rubber bands helped us to explore the ways in which we could expand and translate our new understanding of the cello into the digital mappings. In this way, the models focus on the experiential aspects of this interaction and generate techniques for navigating the complexity of the software through intuition and gesture.

\section{Software and Hardware}

This process, combined with the earlier explorations of the sonic and physical properties of the cello, helped us to develop an understanding of the potential relationships between the physical and the digital. As a result, we were able to imagine strategies in 

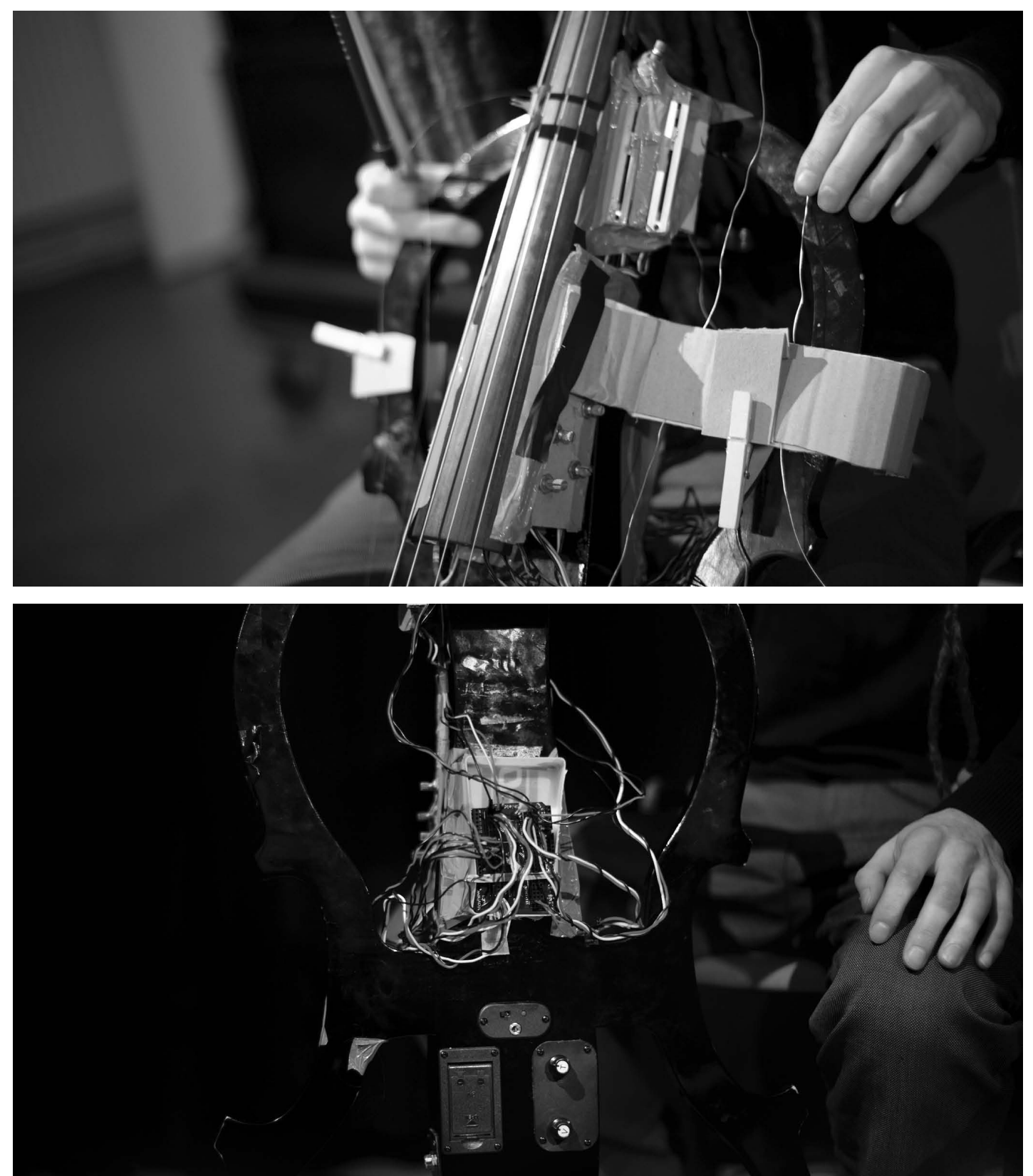

Figures 9 and 10

Mapping the new functionality onto the body of the cello. Images (C) Dan Buzzo. which the gestures of the human body could be used to connect, control, and combine the two, while considering the possible ways in which the software would respond to these interactions.

The following step was to place a microcontroller on the body of the cello as the basis for placing a large number of physical controllers (i.e., sensors, dials, sliders, and buttons). These controllers were then placed temporarily on the body of the cello according to the insights we had gained using tape and cardboard. Each time a controller was reconfigured or moved, the cello was reassembled and played to assess the placement, functionality, and ergonomics of the new controller. These new hardware interfaces 
also functioned as physical representations for the state of the software, allowing the performer to navigate using visual, physical, and sonic feedback.

In addition, software was used to analyze the sound produced by the cello to determine the intentions of the performer and to create both complementary and contrasting transformations to the resulting sound. In this way, the electronic parameters were influenced by the performer's interactions the acoustic interface and created interdependence between the two domains. The introduction of noise and probabilistic functions into this data stream allowed the performer to control the influence and predictability of the instrument's sonic reactions. As a result, a deliberate element of miscommunication was created between the instrument and performer, which could be used to manipulate the sense of continuity within the music, surprising the performer and allowing for discovery and exploration of new sounds.

\section{Collaboration Process Notes:}

Throughout the development of the modified cello, the new reactions of the instrument would encourage me to approach it in different ways, extending pre-existing gestures and techniques while allowing new possibilities to emerge.

This process was encouraged by the reciprocity between playing and building. Similarly, the various software processes used to transform the cello sound gradually developed their own unique characteristics.

The imagined functionality of the software is transferred to the cello body using sensors to provide precise and direct manipulation of the software parameters (see Figures 9 and 10). At first we tried out each sensor placement using cardboard to represent the unfinished state of the instrument and to provide a sense of freedom when making modifications.

The simple, singular processes that we initially chose were grouped and layered to create more interesting, rich, and non-linear responses. These groupings were often chosen to compliment the pre-existing timbres, artifacts, and character of the original processes; however, they were no longer extensions of the original cello sound but entered into a new world of sounds.

\section{The Roles of the Hands}

While making modifications, we primarily focused on the physical relationship between the cello and the performing body so that we might remain alert to issues of balance, counter-balance, and symmetry. The placement and mapping of controllers and sensors were then organized around the bimanual playing techniques of the cello and guitar (i.e., left side of body $=$ pitch/timbre, right side $=$ 


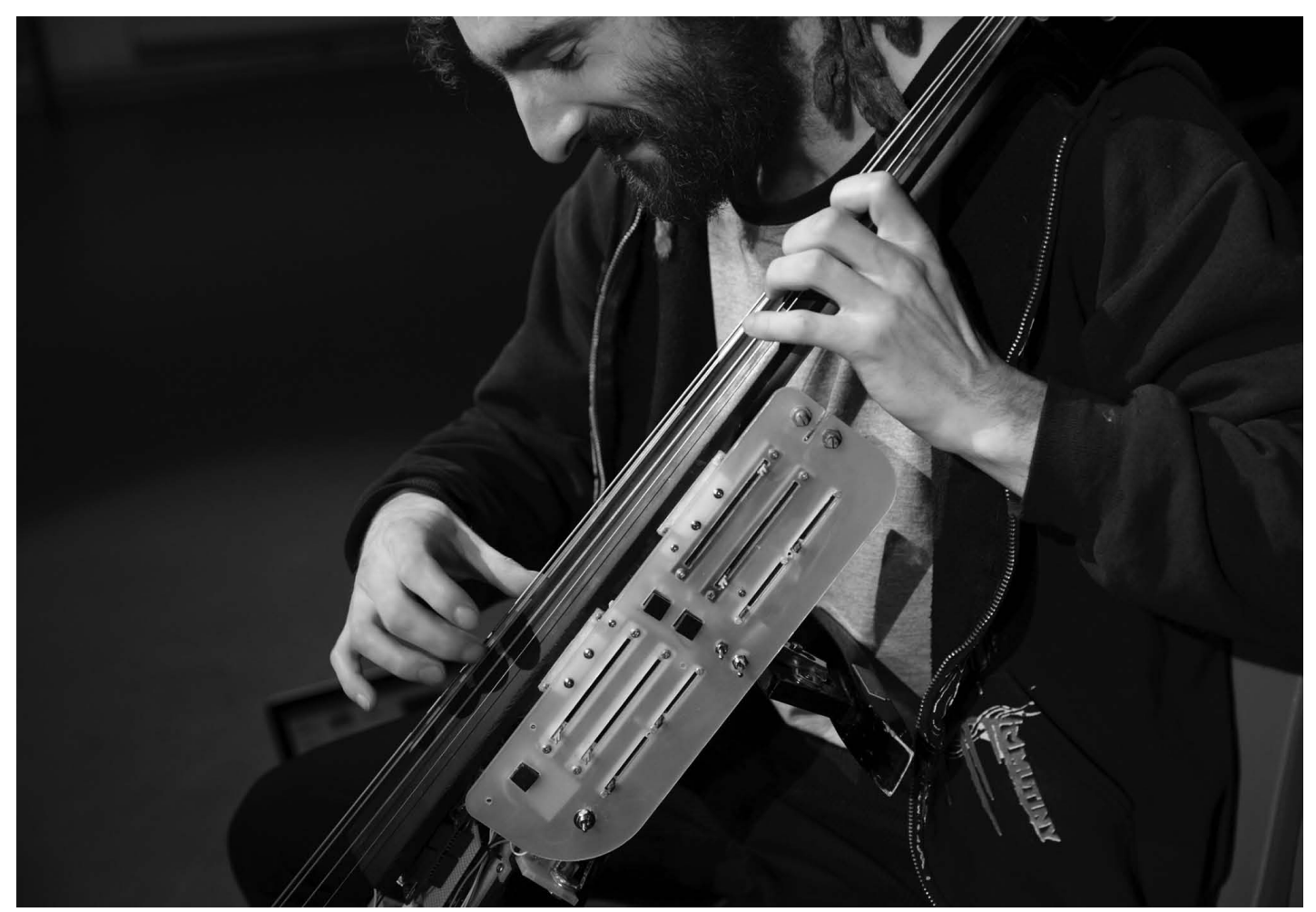

Figure 11 and 12

Fret board sliders and the bow'able dial. Images (C) Dan Buzzo.

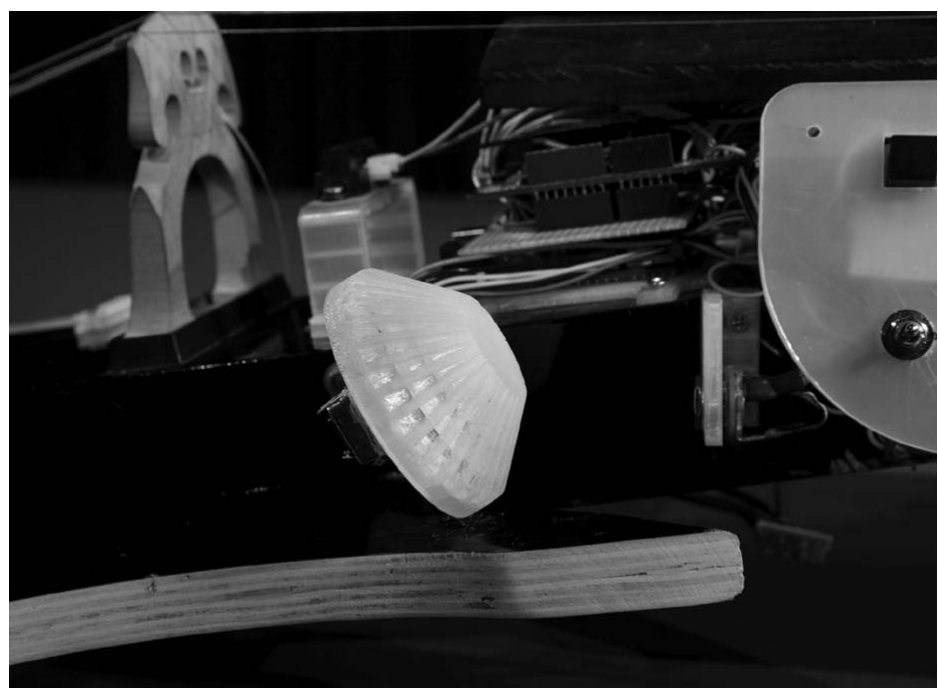

duration/volume). This division of controllers is particularly effective because it complements the characteristics of the cello while incorporating previously obtained instrument techniques.

Evidence of this perspective can be seen in the vertical placement of sliders, which complements the linear and vertical movements of the left hand while providing a visual representation of the software parameters for the musician. The placement of the sliders also acts as fret markers, facilitating orientation and accessibility with the fretting positions of the left hand. 
Furthermore, "bow-able" dials were added, expanding the capabilities of the bowing hand and allowing for fast, unbroken transitions between the control of digital and acoustic elements of the instrument. After each modification, the musician spent time playing the instrument to develop the technical skills necessary to determine the suitability of the changes. This process provided direction for the development of the new instrument by revealing what is physically possible, building on pre-existing abilities and imagining what could be learned. In this way, each parameter evolved its own unique character, informed by its sonic qualities and the physical properties and associations it conveys.

\section{Collaboration Process Notes:}

The position and mappings of the additional sensors are influenced by the bimanual techniques of the cello.

The vertical placement of sliders complements the vertical movements of the left hand while playing. The sliders also provide instant visual feedback regarding the state of the software parameters (see Figure 11). Similarly, the bow-able dial allows the bow to be used to control the software directly in a fluid and non-disruptive manner (see Figure 12).

The material of the old instrument begins to meet, foreshadowing the body of the new cello.

Through the iterative process of playing, reflection, and modification, a new hybrid character emerges from the combination of gestural and sonic possibilities. In this way, the act of playing provided the momentum and direction for the development process of the instrument (see Figures 13 and 14).

\section{Performance}

During the final stage of this project, the instrument was evaluated through a series of performances. Over the course of a year, it was played at about 15 events in various locations in both group and solo situations. Performing with different people encouraged the exploration of different aspects of the instrument, developing new sounds and techniques that might otherwise have been overlooked.

The heightened awareness provided by the live situation and the presence of an audience allows the instrument to be evaluated in a different manner. The shift in perspective and intention that occurred during these performances immediately reveals which aspects of the instrument are successful regarding the effective expression of musical ideas. More specifically, focus moves away from technical thinking and pure exploration toward the structuring of gestures, sounds, and techniques that have been developed during previous stages of practice and development. 


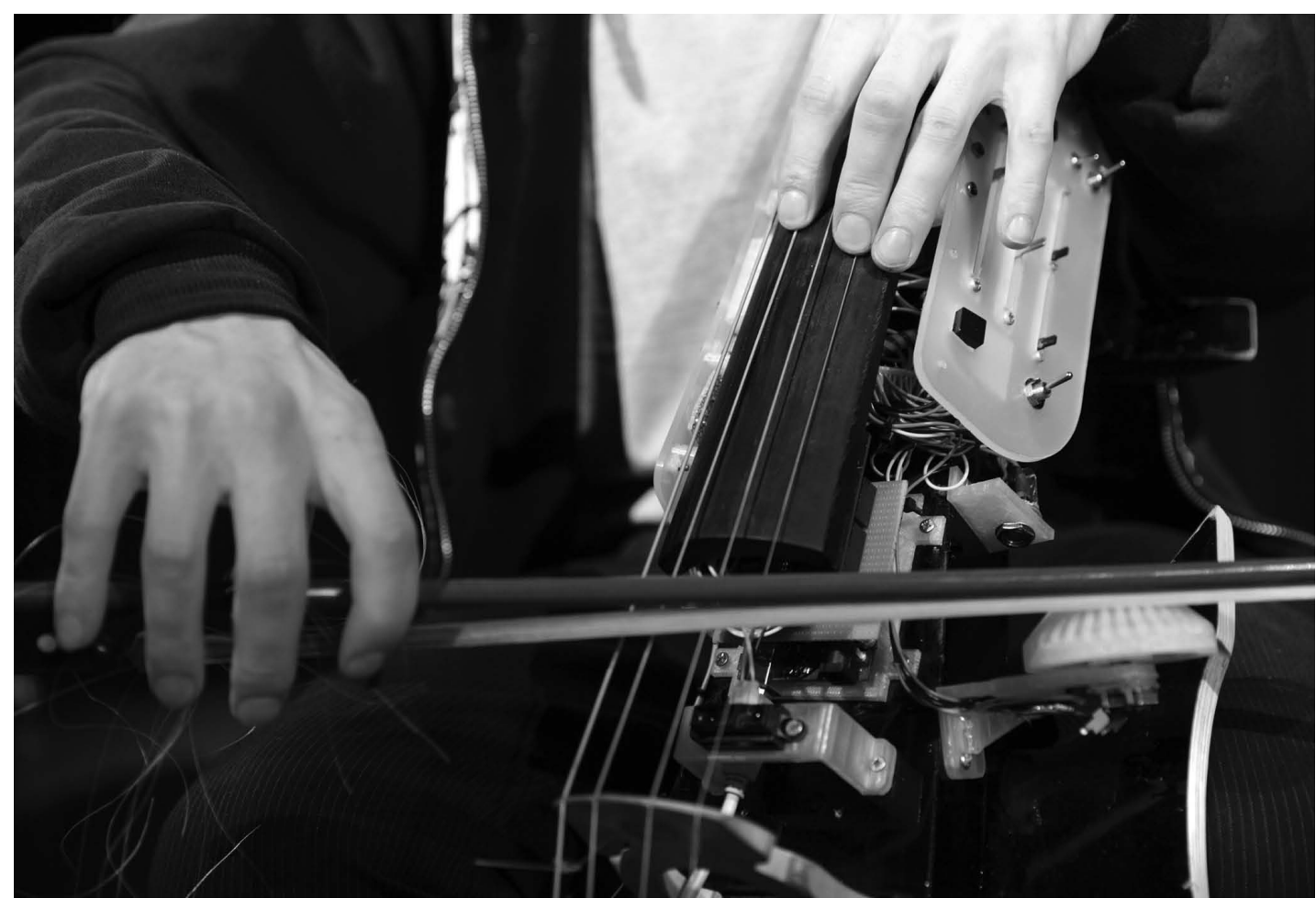

Figure 13

Performance hand positions. Image (C) Dan Buzzo.
This process also highlighted various practical matters related to the logistics of performing with this particular instrument. The large size of the cello can be problematic while traveling, especially by plane; a separate seat has to be purchased for the cello, increasing the cost and complexity of the journey. In comparison with the original cello setup, the modified cello is smaller, combining what had been several separate components into one object. However, the instrument also relies on a laptop and audio interface for interaction to take place between the cello and software. Using an embedded solution and incorporating these elements into the body of the cello would reduce the need for extra baggage and provide a technologically simpler solution. The amount of time and technical thinking required to set up and start playing would be reduced, increasing the time available to focus on sonic and aesthetic issues.

In addition, combining all these separate elements into one object reinforces the perception that the modified cello is a complete instrument. This perception can facilitate communication between the performer and audience as the interaction with the instrument has a clear relation to the already established gestures and techniques of the cello. In this way, the physical and sonic augmentations of the instrument are understood in relation to this framework, allowing the performer to engage and play with the expectations of the audience, transitioning between traditional sounds and techniques to more abstract and less familiar ones. 


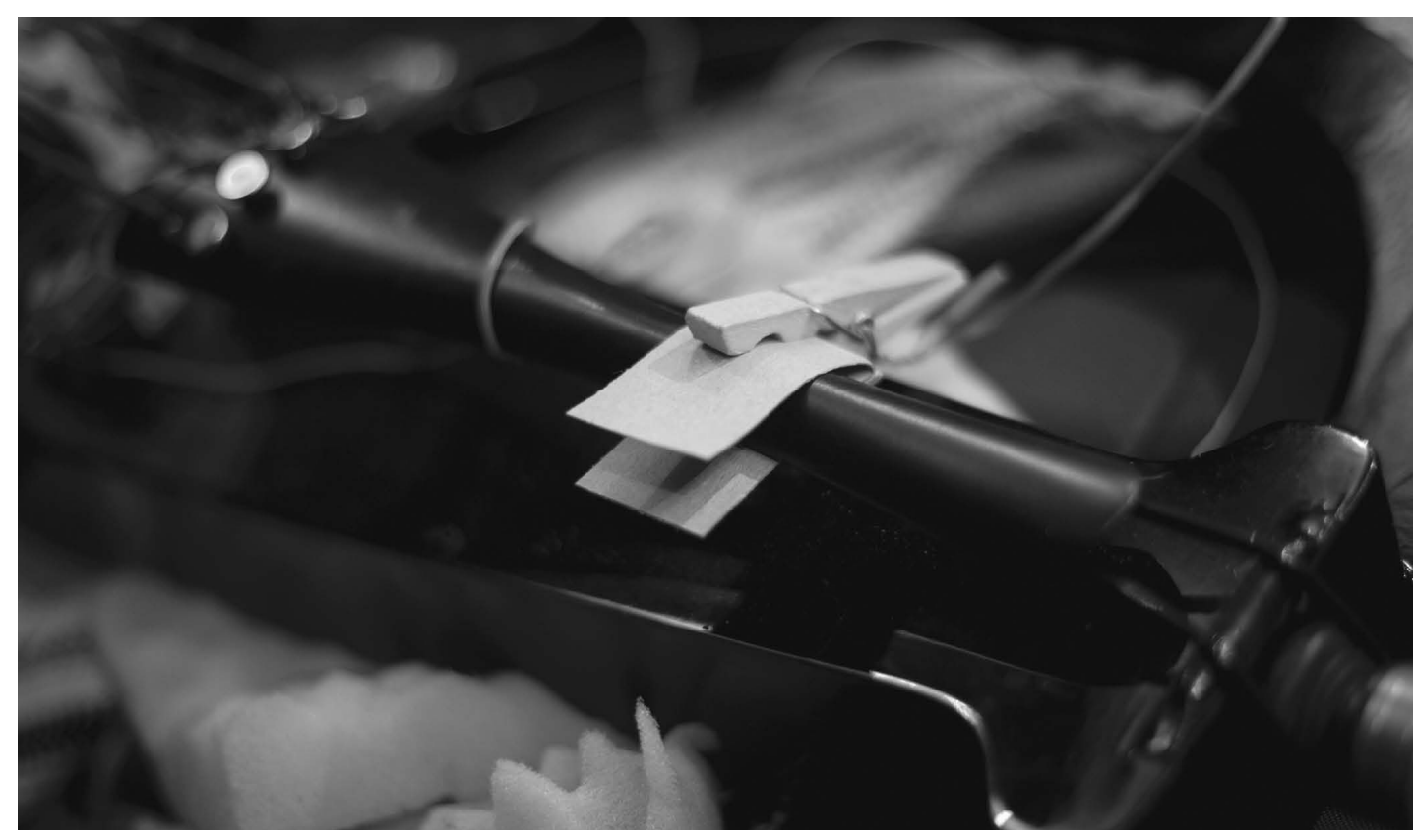

Figure 14

Performance hand positions. Image (C) Dan Buzzo.
Another issue to consider is that the presence of the laptop potentially detracts from the performance, particularly if its purpose is unclear. The proliferation and everyday nature of the laptop computer can be distracting because it destroys the "magical" quality of the performance. Instead of engaging fully in the music, listeners might find themselves thinking about what the computer's role and function are in the performance. In this way, the presence of the laptop can reduce the sense of authenticity of the performance. It becomes a point of distraction, undermining the listener's experience of the musician's actions and intentions, along with the resulting sound, as the focal point of the performance.

\section{Collaboration Process Notes:}

The process of adapting to the modifications of the cello requires a shift in perspective from being technically oriented toward engaging a more musical mode of thought. This shift often takes time, practice, and perseverance to achieve the necessary experience and understanding.

Performing with the modified cello helped to clarify my intentions, evaluate the instrument's effectiveness, and inspire new features. The concentration required by the live situation encouraged me to be more decisive, with less time available for doubt and hesitation to develop in my mind.

During this process, the instrument and music began to evolve as I became more familiar with the particular characteristics of the instrument. By exploring the boundaries of the instrument's capabilities and developing intuitive knowledge through play and practice, I began to focus on larger- and smaller-scale structures and movements. 


\section{Reassessing the Modified Cello}

In his talk at RTD 2015, Tim Ingold described the creative process as more akin to attentional wayfaring than proceeding in a straight line. ${ }^{10}$ We find that Ingold's notion adds depth to our own experiences with the development of the modified cello. Our collaborative design process has generated more possibilities than solutions, and we have moved through them by carefully paying attention "as it unfolds." As Ingold stated in his provocation, "[t]he power of the imagination lies not in mental representation nor in a capacity to construct images in advance of their material enactment; rather, imagining is a movement of opening, not of foreclosure, and what it brings forth are not endings but beginnings."

Looking back on this process with these new insights, we have the opportunity to reassess the modified cello as an instrument in its own right. Visually, it remains attached to the strong cultural image of the cello, but it is a strange and mutated one (see Figure 15). Just as with a traditional cello, its size and the posture required to play in the upright position restricts the performer's movement, requiring the support and balance of the instrument.

Over time, an additional way of playing has emerged: By laying the instrument flat on its back, the performer is free to move around the instrument and explore different techniques. This change in orientation alters the relationship between the performer and instrument, leading to a more reflective playing style. The bimanual locations on the left and right sides of the instrument's body become more flexible and interchangeable.

This new freedom of movement has led to the possibility of a more percussive style of playing, incorporating various objects, such as drum sticks and brushes, and the use of motors to interact with the cello. The performer can make faster movements between different parts of the instrument that were previously inaccessible, increasing the potential music that can be produced to generate a more dynamic set of contrasting textures and sounds.

Given that the initial work focused on exploring the traditional stance in more ergonomic ways, this development is somewhat ironic. It can be seen as an aspect of the iterative process, during which the interplay between playing and modification reveals and accentuates aspects of the instrument. The traditional stance informed the rebuilding of the cello, and then the resulting cello reconfigured the playing technique and mapping. This development process remains ongoing, and each discovery represents a beginning in a way that mirrors Ingold's position.

\section{Collaboration Process Notes:}

The software for this instrument initially was designed to provide unpredictability, but as I gained experience, I started to predict its responses and behaviors. As a result, the music 


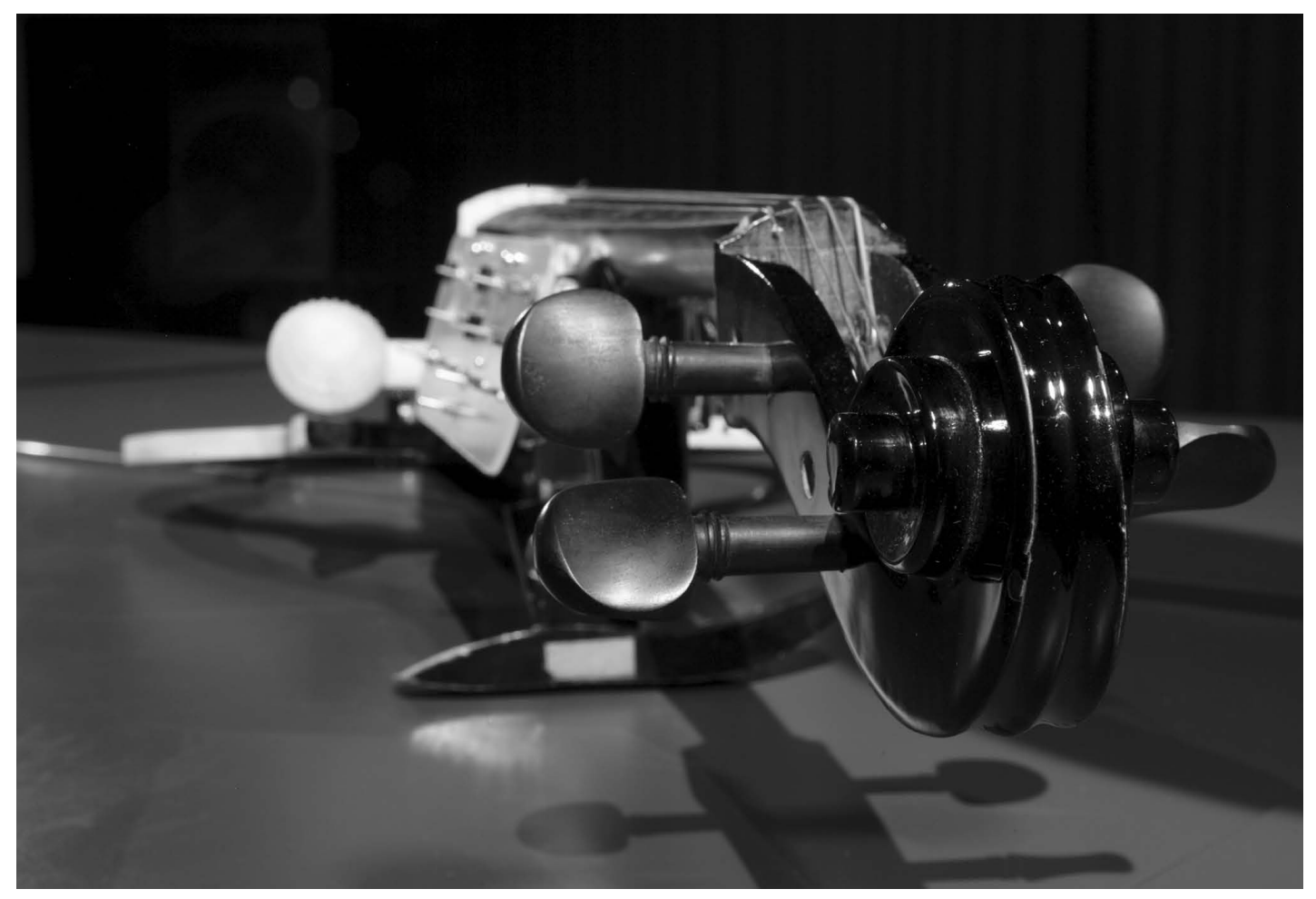

Figure 15

The finished cello resting on a table. Image () Dan Buzzo. became more controlled-more narrating and lyrical—and allowed communication between instrument and performer to take place on a deeper level.

In addition, when the instrument is producing less predictable responses, as a result of the state of the software, my focus is shifted toward larger scale gestures because the influence and directness of the acoustic interface is reduced.

As a more abstract sound world becomes available. I can play with how much the sound relates to or deviates from the natural acoustic sound of the cello. This blurring of causality excites the imagination and brings a newness to the music.

\section{What Remains}

Throughout this process, we have considered the instrument in the light of a desire to make a new kind of music. Over time, each function and element has found its place on the modified body of the cello, and these modifications have in return changed how we might want to play it. The physical remaking of the cello has resulted in a new unified body, where the new and old aspects of the instrument are joined into a new whole. 
In retrospect, the process can be described like this: The cello initially presents as a well-known whole, a finished instrument. Through the disassembling and adding of new powers and functions, it metaphorically breaks apart and becomes fractured, and we have the opportunity to consider it in its elements and units. Suddenly, each string and fret has to argue for its own inclusion, just as each new software component does. As this process moves along, the cello is continuously played and experimented with, but where the experiments fragment the cello, the playing acts as the driver to allow the instrument to come together again as a new whole. This push-pull process continues until the cello can finally re-emerge as a fundamentally changed instrument, stable in its new form and functionality.

At this point the instrument is ready to become a professional performing and touring vehicle for the musician; our thoughts therefore return to Joel Ryan and his observation: that "the performance itself becomes the test bed, where the unexpected curves into your plans and you are forced to reconsider everything-from your premises to the gage of wire in your cables." ${ }^{11}$ The rest of the process will be seen on stage, in the dressing rooms, and in the waiting areas of airports, as the new instrument proves itself musically and performatively.

Kristina Andersen teaches the combined MA between STEIM and Sonology in Den Haag, as well as maintaining her own practice.

Dan Gibson is an English musician and sound artist.

\section{Acknowledgements}

11 Ryan and Andersen, "821 words and 20 images."

We thank Dan Buzzo for permitting us to use the photos in this article. 